Revue

Revue de l'histoire des religions

de Ihistoire des religions

$1 \mid 2014$

Varia

\title{
Stéphane Ratti, Polémiques entre paiens et chrétiens
}

Paris, Les Belles Lettres (« Histoire », 112), 2012

Emmanuel Soler

\section{CpenEdition}

Journals

Édition électronique

URL : http://journals.openedition.org/rhr/8212

DOI : $10.4000 /$ rhr.8212

ISSN : 2105-2573

Éditeur

Armand Colin

Édition imprimée

Date de publication : 1 mars 2014

Pagination : 135-137

ISBN : 978-2200929107

ISSN : 0035-1423

Référence électronique

Emmanuel Soler, «Stéphane Ratti, Polémiques entre païens et chrétiens », Revue de l'histoire des religions [En ligne], 1 | 2014, mis en ligne le 13 mai 2014, consulté le 22 septembre 2020. URL : http:// journals.openedition.org/rhr/8212; DOI : https://doi.org/10.4000/rhr.8212

Ce document a été généré automatiquement le 22 septembre 2020

Tous droits réservés 


\section{Stéphane Ratti, Polémiques entre paiens et chrétiens}

Paris, Les Belles Lettres (« Histoire », 112), 2012

Emmanuel Soler

\section{RÉFÉRENCE}

Stéphane Ratti, Polémiques entre païens et chrétiens, Paris, Les Belles Lettres (« Histoire », 112), 2012, 289 p., 22 cm, 25 €, ISBN-13 978-2-251-38112-1.

1 La question centrale qui est présentée par Stéphane Ratti dans l'introduction de son livre est celle de la relation entre la fiction historique dans l'Histoire Auguste et la pensée religieuse sous-jacente dans cette œuvre tardive composée d'une trentaine de biographies d'empereurs, des $\mathrm{II}^{\mathrm{e}}$ et $\mathrm{III}^{\mathrm{e}}$ siècles. D'emblée, l'auteur place l'Histoire Auguste au cœur des luttes idéologiques et arétalogiques entre les chrétiens et les païens, la biographie fictive étant, pour les uns et pour les autres, le moyen d'affirmer l'ancienneté de leurs valeurs morales et la pertinence de leurs positions religieuses.

2 Cette entrée en matière est suivie d'un état de l'historiographie relative au contexte politique et religieux dans lequel l'Histoire Auguste a été produite. Fort justement, Stéphane Ratti rappelle que toute une mouvance historienne, en partie de confession chrétienne, pour une bonne part anglo-saxonne, a profité des acquis de l'anthropologie brownienne pour remettre en cause des travaux qui avaient établi que l'Histoire Auguste portait la marque « d'un parti pris en faveur d'un paganisme sur la défensive » et plus largement pour remettre en cause toute idée qu'il ait pu exister une résistance païenne, intellectuelle, voire une "réaction païenne", selon l'expression mise en exergue, entre autres, par P. de Labriolle. De même, lorsqu'il s'agit de la datation de l'Histoire Auguste et de la détermination de son auteur, les affirmations de S. Ratti, échafaudées par des travaux antérieurs (par exemple Écrire l'Histoire à Rome, 2009; Antiquus error. Les ultimes feux de la résistance païenne, 2010), selon lesquelles l'œuvre a été écrite entre 392 et 394 par Nicomaque Flavien senior, l'un des adversaires de l'empereur Théodose, lors de la 
bataille de la Rivière froide, en 394, sont recevables. En revanche, on ne peut qu'être dubitatif lorsque $\mathrm{S}$. Ratti considère que la religion de Prétextat n'a pas grand-chose à voir avec le mysticisme de l'empereur Julien et lorsqu'il affirme que Nicomaque Flavien devait «sans doute être un adepte comme beaucoup d'autres d'une religion civique ordinaire ». Pour se convaincre du fait que Prétextat avait très certainement adopté la foi païenne de l'empereur Julien, il faut réellement se pencher sur les inscriptions relatives à celui qui fut proconsul d'Achaïe, sous l'empereur Julien, sur ses initiations multiples, et prendre en compte les affirmations d'Eunape, qui a rapporté que Prétextat reçut l'initiation éleusinienne de Nestorius, le hiérophante d'Éleusis, qui soutint l'usurpation de Julien, en Gaule. Quant à Nicomaque Flavien, on ne peut que relever la contradiction entre la première affirmation de $S$. Ratti et ce qu'il développe dans la suite de l'introduction et dans la seconde partie de l'ouvrage, à savoir que Nicomaque Flavien fut adepte du néoplatonisme, de ce néoplatonisme (en fait, ritualiste, théurgique) qui fut conçu par certains, «à la suite de Julien, comme un haut lieu de résistance au christianisme », selon les propres termes de S. Ratti.

Le titre de la première partie de l'ouvrage, « le malaise païen » n'est pas complètement satisfaisant au regard de la haine réciproque des chrétiens et des "philosophes » qui, selon S. Ratti, transparaît dans les productions littéraires du début du ve siècle et qui explique, selon lui, les traits antichrétiens présents dans le Querolus, Le Grincheux, une comédie anonyme dédiée à un "païen militant", Rutilius Namatianus, préfet de la Ville, en 414. En effet, la première partie porte davantage sur les formes de résistance intellectuelles païennes que sur le «malaise païen». De fait, S. Ratti rappelle tout d'abord que les intellectuels ou les lettrés païens s'exprimaient dans un contexte de contrainte et de peur qui nécessitait de leur part une certaine prudence. Ensuite, il en vient à la course aux exempla, à la surenchère morale à laquelle se livrèrent les intellectuels chrétiens et païens, ces derniers cherchant dans l'histoire impériale des modèles à opposer à ceux représentés par les martyrs chrétiens. Enfin la première partie se clôt sur trois chapitres consacrés au théâtre comique, présenté comme un lieu de la polémique antichrétienne. C'est fort justement que S. Ratti insiste sur la permanence des jeux et des spectacles dans l'Empire romain tardif, sous les empereurs chrétiens et sur le fait que les intellectuels païens, auteurs de comédies ont pu utiliser la comédie et le théâtre pour railler les institutions, les dogmes et les comportements chrétiens. On peut cependant se demander dans quelle mesure les critiques antichrétiennes plus ou moins explicites dans des comédies comme Querolus s'apparentaient véritablement à une "polémique antichrétienne " étant donné que publiquement, sur les scènes de théâtre, les rites chrétiens, comme d'ailleurs les dieux du paganisme étaient ouvertement moqués, au grand dam des Pères de l'Église et des empereurs chrétiens qui ne pouvaient pas réellement s'opposer à des parodies qu'ils jugeaient insultantes pour la foi chrétienne (voir la loi du Code Théodosien qui date du 29 juin $394, \mathrm{XV}, 7,12)$. Le fait que le christianisme soit devenu l'objet de parodies théâtrales a pu signifier tout simplement, même si les auteurs de comédies n'étaient pas favorables à cette religion, que le christianisme constituait désormais l'un des fondements de la vie quotidienne et religieuse des cités.

4 La seconde partie, comme l'introduction l'annonce, est focalisée sur la figure de Nicomaque Flavien, sur l'identification de ce sénateur "païen» du IV siècle avec l'auteur de l'Histoire Auguste. Cette partie, en forme d'argumentaire, érudit, parfois pesant en raison des impératifs de la démonstration, est sous-tendue par une force de 
conviction (dont on ne dira jamais assez qu'elle est nécessaire à l'écriture de l'Histoire) qui emporte l'adhésion sur de nombreux points. On retiendra que Nicomaque Flavien fut très certainement la cible du poème anonyme Carmen contra paganos, qu'il fut à coup sûr un adepte du néoplatonisme dont certains aspects transparaissent dans l'Histoire Auguste, qu'il fut très probablement le rédacteur (identifié comme tel par l'emploi particulier de clausules) de certaines lois recensées dans le Code Théodosien, loi sur les héritages, loi contre l'homosexualité masculine dont on trouve également des échos dans l'Histoire Auguste. De même on retiendra que dans l'Histoire Auguste, la mention du sacrifice de leur chevelure par les femmes d'Aquilée afin de fabriquer des cordages pour les armes de trait, lors du siège de la cité par Maximin le Thrace, s'explique par la volonté de l'auteur de cette Histoire de rappeler les valeurs de fides et de deuotio chères à la tradition (païenne) romaine et, de manière implicite, en s'en moquant, l'interdiction de se raser la chevelure faite aux femmes chrétiennes, par Théodose, en 390.

Pour conclure, l'ouvrage de S. Ratti s'inscrit heureusement dans la continuité de l'ouvrage de Pierre Chuvin, Chronique des derniers païens (1990) et présente, entre autres, le mérite de s'opposer à l'occultation, par certains courants académiques, de la résistance des "philosophes » à la christianisation de l'Empire. De ce point de vue, on ne peut que souscrire aux remarques très critiques de $S$. Ratti sur l'ouvrage d'A. Cameron, The Last Pagans (2011). En revanche, Polémiques entre païens et chrétiens pèche très certainement sur certains points par des excès dans l'argumentation. De même, on ne peut que souligner la contradiction qu'il y a entre le fait de qualifier Nicomaque Flavien de "philosophe néoplatonicien » et celui de ne reconnaitre dans ses positions religieuses que la seule adhésion à la religion traditionnelle romaine.

\section{AUTEURS}

\section{EMMANUEL SOLER}

Université de Rouen 